\title{
The anti-diabetic drug metformin inhibits pancreatic cancer cell proliferation in vitro and in vivo: Study of the microRNAs associated with the antitumor effect of metformin
}

\author{
KIYOHITO KATO $^{1}$, HISAKAZU IWAMA ${ }^{2}$, TAKUMA YAMASHITA ${ }^{1}$, KIYOYUKI KOBAYASHI ${ }^{1}$, \\ SHINTARO FUJIHARA ${ }^{1}$, TAKAYUKI FUJIMORI ${ }^{1}$, HIDEKI KAMADA ${ }^{1}$, \\ HIDEKI KOBARA $^{1}$ and TSUTOMU MASAKI ${ }^{1}$ \\ ${ }^{1}$ Department of Gastroenterology and Neurology, Faculty of Medicine, and ${ }^{2}$ Life Science Research Center, \\ Kagawa University, Kita-gun, Kagawa Prefecture 761-0793, Japan
}

Received August 31, 2015; Accepted October 13, 2015

DOI: 10.3892/or.2015.4496

\begin{abstract}
Recent studies suggest that metformin, which is a commonly used oral anti-hyperglycemic agent of the biguanide family, may reduce cancer risk and improve prognosis, yet the detailed mechanisms by which metformin affects various types of cancers, including pancreatic cancer, remain unknown. The aim of the present study was to evaluate the effects of metformin on human pancreatic cancer cell proliferation in vitro and in vivo, and to study microRNAs (miRNAs) associated with the antitumor effect of metformin. We used the human pancreatic cancer cell lines Panc1, PK1 and PK9 to study the effects of metformin on human pancreatic cancer cells. Athymic nude mice bearing xenograft tumors were treated with or without metformin. Tumor growth was recorded after 5 weeks, and the expression of cell cycle-related proteins was determined. In addition, we used miRNA microarray tips to explore the differences in the levels of miRNAs in Panc1 cells and xenograft tumors treated with metformin or without. Metformin inhibited the proliferation of Panc1, PK1 and PK9 cells in vitro. This inhibition was accompanied by a strong decrease in G1 cyclins (particularly in cyclin D1) and retinoblastoma protein $(\mathrm{Rb})$ phosphorylation. In addition, metformin reduced the phosphorylation of epidermal growth factor receptor (EGFR), particularly the phosphorylation of EGFR at Tyr845, and insulin-like growth factor 1 receptor
\end{abstract}

Correspondence to: Professor Tsutomu Masaki, Department of Gastroenterology and Neurology, Faculty of Medicine, Kagawa University, 1750-1 Ikenobe Miki-cho, Kita-gun, Kagawa Prefecture 761-0793, Japan

E-mail: tmasaki@med.kagawa-u.ac.jp

Abbreviations: miRNAs, microRNAs; Cdk4, cyclin-dependent kinase 4; Cdk6, cyclin-dependent kinase 6; $\mathrm{Rb}$, retinoblastoma protein

Key words: pancreatic cancer, metformin, G0/G1 arrest, microRNAs, EGFR, IGF-1R
(IGF-1R) in vitro and in vivo. miRNA expression was markedly altered by the treatment with metformin in vitro and in vivo. Our results revealed that metformin inhibits human pancreatic cancer cell proliferation and tumor growth, possibly by suppressing the cell cycle-related molecules via alteration of miRNAs.

\section{Introduction}

Pancreatic cancer is now the fifth leading cause of cancerrelated deaths, and the annual mortality is estimated to be more than 20,000 in Japan. The 5-year survival rate of pancreatic cancer is as low as $5.5 \%$, and the poor prognosis is attributed to the difficulty of detecting the disease at an early stage, the high malignant potential and the propensity of the cancer to metastasize, and the high resistance level to antitumor agents.

Metformin is an oral biguanide drug introduced into clinical practice in the 1950s for the treatment of type 2 diabetes. According to a recent epidemiological survey, metformin has significant effects on tumorigenesis (1). For instance, it is reported that patients with type 2 diabetes who are prescribed metformin have a lower risk of cancer compared to patients who do not take metformin (2). In addition, numerous interventional clinical trials have tested the efficacy of metformin in various human cancers, including pancreatic cancer. Basic investigations have also been performed, and have shown that metformin may inhibit the proliferation of prostate (3), breast $(4,5)$, colon $(5,6)$ and pancreatic cancer $(7)$ cells. Metformin was also found to inhibit the tumor growth of prostate (3) and pancreatic cancer (8) in xenograft models. In a recent study, we reported that metformin inhibited the proliferation of gastric cancer cells in vitro and in vivo (9). However, the detailed mechanism of the suppression of pancreatic cancer growth by metformin remains relatively unknown.

MicroRNAs (miRNAs) are small, non-coding RNA molecules of 17-27 nucleotides in length, and are involved in gene regulation at the post-transcriptional level. miRNAs play critical roles in diverse biological processes, such as development and differentiation, control of cellular proliferation, stress response and metabolism (10). Recent studies have 
shown that miRNAs are aberrantly expressed in virtually all types of human cancer; that miRNAs may function as tumor suppressors or oncogenes; and that alteration in miRNA expression may play a critical role in tumorigenesis and cancer progression (11). miRNAs seem to be very significant prognostic factors in patients with different tumors and thus could be useful biomarkers for treatment (12).

In the present study, we showed that metformin has an effective anticancer effect on pancreatic cancer, and we examined the expression of cell cycle-related molecules in relation to the mechanism of the antitumor effect of metformin. In addition, we identified several miRNAs associated with the antitumor effects of metformin.

\section{Materials and methods}

Chemicals. Metformin (1,1-dimethylbiguanide) was purchased from Dainippon Sumitomo Pharma Inc. (Osaka, Japan). The Cell Counting Kit-8 (CCK-8) was purchased from Dojindo Laboratories (Kumamoto, Japan), and all other chemicals were obtained from Sigma Chemical Co. (Tokyo, Japan).

Antibodies. The antibodies used were anti- $\beta$-actin monoclonal antibody (A5441, used at 1:3,000; Sigma-Aldrich Co., St. Louis, MO, USA), cyclin D1 (RB-9041, used at 1:1,000; Thermo Fisher Scientific K.K., Waltham, MA, USA), cyclin E (used at 1:1,000; BD Biosciences, San Jose, CA, USA), CDK6 (sc-177, used at 1:1,000), CDK4 (sc-749, used at 1:2,500), phosphorylated retinoblastoma protein $(\mathrm{Rb})(\mathrm{sc}-50$, used at 1:1,000) (all from Santa Cruz Biotechnology, Santa Cruz, CA, USA), and secondary horseradish peroxidase-linked anti-mouse and anti-rabbit IgG antibodies (used at 1:2,000; GE Healthcare, Ltd., Buckinghamshire, UK).

Cell lines and culture. The human pancreatic cancer cell lines PK1, PK9 and Panc1 were obtained from the Japanese Cancer Research Resources Bank (Tokyo, Japan). Cells were grown in RPMI-1640 medium (Gibco Invitrogen, Carlsbad, CA, USA) supplemented with $10 \%$ fetal bovine serum (FBS) (533-69545; Wako, Japan), and penicillin-streptomycin (100 mg/l; Gibco Invitrogen) in a humidified atmosphere of $5 \% \mathrm{CO}_{2}$ at $37^{\circ} \mathrm{C}$.

Cell proliferation assay. Cell proliferation assays were performed with a CCK-8 kit according to the manufacturer's instructions. Cells of each cell line $\left(1 \times 10^{4}\right)$ were seeded into the well of a 96-well plate and were cultured in $100 \mu \mathrm{l}$ of RPMI-1640 supplemented with $10 \%$ FBS. After $24 \mathrm{~h}$, the seeded cells were treated by addition of metformin (5 or $10 \mathrm{mM}$ ) to the culture medium or left untreated (controls). At the indicated time points, the medium was exchanged for $110 \mu \mathrm{l}$ of RPMI-1640 with CCK-8 reagent (10 $\mu \mathrm{l} \mathrm{CCK-8}$ and $100 \mu \mathrm{l}$ RPMI-1640), and the cells were incubated for $2 \mathrm{~h}$. Absorbance was measured for each well at a wavelength of $450 \mathrm{~nm}$ using an auto-microplate reader.

Cell and tissue lysates. The lysate assay was performed according to the methods described in our previous studies $(9,13)$. All steps were carried out at $4^{\circ} \mathrm{C}$. Protein concentrations were measured using a dye-binding protein assay based on the Bradford method.
Gel electrophoresis and western blot analysis. Sodium dodecyl sulfate-polyacrylamide gel electrophoresis (SDS-PAGE) was performed according to the method of Laemmli (14), and the western blot analysis was performed as described by Towbin et al (15) using primary antibodies and HRP-conjugated secondary antibodies. Immunoreactive proteins were visualized with an enhanced chemiluminescence detection system (Amersham Life Sciences, Tokyo, Japan) on X-ray film.

Xenograft model analysis. Animal experiments were performed according to the guidelines of the Committee on Experimental Animals of Kagawa University. We purchased 30 male athymic mice (BALB/c-nu/nu, 8 weeks old, 20-25 g) from Japan SLC (Hamamatsu, Japan). The animals were maintained under specific pathogen-free conditions using a laminar airflow rack and had continuous free access to sterilized food [ $\gamma$-ray-irradiated food CL-2 (Clea, Tokyo, Japan)] and autoclaved water. Each mouse was inoculated with Panc1 cells $\left(5 \times 10^{7}\right.$ cells/animal) subcutaneously in the flank region. Two weeks later, the xenografts were identifiable as masses of $>5 \mathrm{~mm}$ in maximal diameter in all recipients.

The animals were randomly assigned to three groups. Animals in the metformin-treated groups received intraperitoneal (i.p.) administration of 1 or $2 \mathrm{mg} /$ body metformin/day, 5 times a week for 5 weeks. Animals of the control group were administered only phosphate-buffered saline (PBS) $(n=10)$. After initiation of the administration of metformin, the tumor growth was monitored by the same investigator (K.K. and T.M.), and the tumorigenesis of the pancreatic cancer was monitored every day. The tumor size was measured weekly by measuring the two greatest perpendicular tumor dimensions. To examine the significance of the differences between growth curves in the present study, all the measurements of tumor volume for each growth curve from the start of the treatment to the end, typically $\sim 30$ observations, were analyzed by one-way analysis. The tumor volume was calculated as follows: Tumor volume $\left(\mathrm{mm}^{3}\right)=\left[\right.$ tumor length $(\mathrm{mm}) \times$ tumor width $\left.(\mathrm{mm})^{2}\right] / 2$. All animals were sacrificed on day 35 after treatment. All animals were alive during the observation.

Antibodyarrays of phospho-RTK. A RayBio ${ }^{\mathrm{TM}}$ Human Phospho Array kit (catalog no. ARY 001) was purchased from RayBiotech Inc. (Norcross, GA, USA). The assay for the phospho-RTK array was performed according to the manufacturer's instructions. This assay allows the screening of 42 different phosphorylated human RTKs. Capture and control antibodies were spotted in duplicate on nitrocellulose membranes. Lysates prepared from the cells and tumor tissues were diluted and incubated with the array's membranes. After allowing the material to bind with the extracellular domain of both phosphorylated and unphosphorylated RTKs, the unbound material was washed away. A pan anti-phospho-tyrosine antibody conjugated to horseradish peroxidase was then used to detect phosphorylated tyrosines on activated receptors by chemiluminescence. Finally, the density of the immunoreactive band obtained on the RTK arrays was analyzed by densitometric scanning with a Tlc scanner (Shimizu Co., Ltd., Kyoto, Japan).

EGFR phosphorylation antibody array. To assess whether the phosphorylation sites of epidermal growth factor receptor 
A

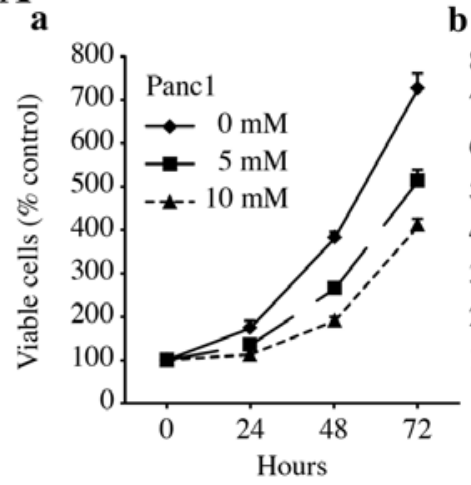

b

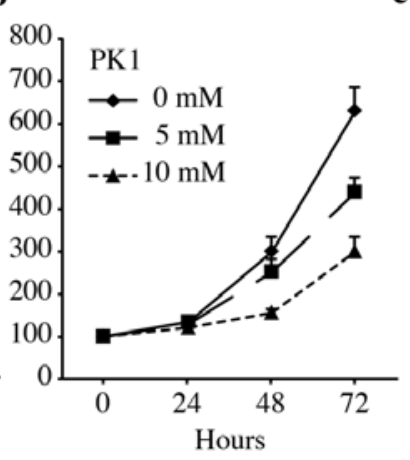

c

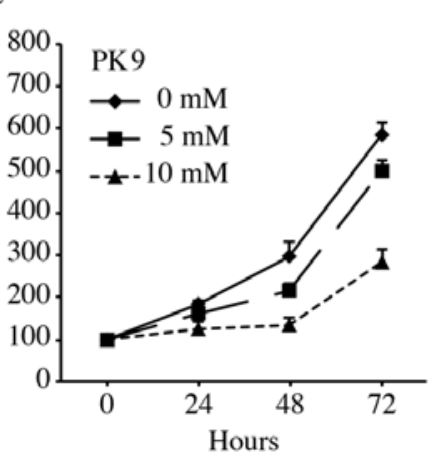

B

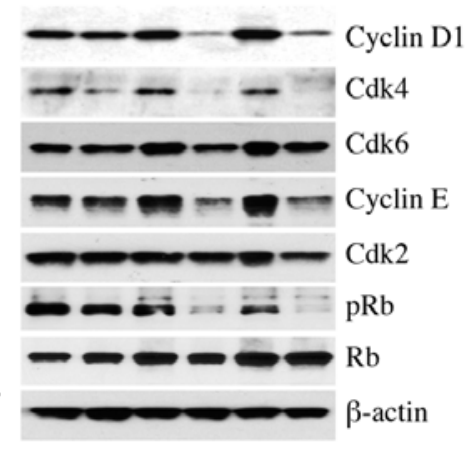

Figure 1. Metformin inhibits the proliferation of cultured pancreatic cancer cells. (A) (a) Panc1, (b) PK1 and (c) PK9 cells were seeded at 10,000 cells/well in a 96-well plate and the agents were added at time $0 \mathrm{~h}$. A Cell Counting Kit- 8 assay was performed daily from time 0 to $72 \mathrm{~h}$ as described in Materials and methods. The data points represent the mean cell number from three independent cultures, and the error bars represent standard deviations. For each cell line, the conditions at 48 and $72 \mathrm{~h}$ were significantly different when compared to the control $(0 \mathrm{mM})$, based on an analysis using Student's t-test $(\mathrm{P}<0.05)$. (B) Metformin affects the expression levels of the various cell cycle-regulatory proteins in the G0/G1 cycle in Panc1 cells. Western blotting of cyclin D1, Cdk4, Cdk6, cyclin E, Cdk2, phosphorylated Rb (pRb) and Rb in Panc1 cells was performed at 24, 48 and $72 \mathrm{~h}$ after the addition of $10 \mathrm{mM}$ metformin (Met) for the indicated times. $\beta$-actin was used as a loading control.

(EGFR) are regulated by the antitumor effect of metformin, the RayBio Human EGFR Phosphorylation Antibody Array (RayBiotech Inc.) was used according to the manufacturer's protocol. This method is a dot-blot-based assay which enables detection and comparison of 17 different specific phosphorylation sites in the human EGFR family. This array was used to add metformin-treated or untreated cell and tumor tissue lysates to the antibody array membranes. The antibody array membranes were washed and a cocktail of biotin-conjugated anti-EGFR was used to detect phosphorylated ErbB1-B4 and pan ErbB1-B4. After incubation with HRP-streptavidin, the signals were visualized by chemiluminescence.

Finally, the densities of the immunoreactive bands obtained on the RTK arrays were analyzed by densitometric scanning with a Tlc scanner.

Analysis of the miRNA microarray. The samples of tumor tissues and cancer cell lines were processed for total RNA extraction with an miRNeasy Mini kit (Qiagen) according to the manufacturer's instructions. RNA samples typically showed A260/280 ratios between 1.9 and 2.1. The RNA integrity was further confirmed by use of an Agilent 2100 Bioanalyzer (Agilent Technologies, Palo Alto, CA, USA).

After RNA measurement on an RNA 6000 Nano kit, the samples were labeled using a miRCURY Hy3/Hy5 Power labeling kit and were hybridized on a human miRNA Oligo chip (v.14.0; Toray Industries Inc., Kanagawa, Japan). Scanning was performed with a 3D-Gene Scanner 3000 (Toray Industries Inc.). 3D-Gene extraction software, version 1.2 (Toray Industries Inc.) was used to read the raw intensity of the image. To determine the change in microRNA expression between metformin-treated and control samples, the raw data were analyzed via GeneSpringGX version 10.0 (Agilent Technologies). Samples were first normalized relative to 28sRNA and baseline corrected to the median of all samples.

Replicate data were consolidated into two groups based on metformin treatment and control, and were organized using the hierarchical clustering and analysis of variance (ANOVA) functions in the GeneSpring software. Hierarchical clustering was carried out by use of the clustering function (condition tree) and Euclidean correlation as a distance metric. Two-way ANOVA analysis and asymptotic P-value computation without any error correction on the samples was performed to search for miRNAs which varied most prominently across the different groups. The cut-off for the P-values was set to 0.05 . Only changes $>50 \%$ in at least one of the time points for each sample were considered significant. All the analyzed data were scaled by global normalization. The statistical significance of differentially expressed miRNA was analyzed by the Student's t-test.

Statistical analysis. All analyses were performed using the computer-assisted JMP8.0 (SAS Institute, Cary, NC, USA). Paired analysis between two groups was performed using a t-test. A P-value of 0.05 was considered to indicate a significant difference between groups.

\section{Results}

Metformin inhibits the proliferation of human pancreatic cancer cells. To evaluate the effect of the growth activity of metformin on human pancreatic cancer cells in vitro, we examined the effect of metformin on proliferation in three pancreatic cancer cell lines, namely, PK1, PK9 and Panc1. Cells were grown in $10 \%$ FBS and were treated with 5 or $10 \mathrm{mM}$ metformin or left untreated (controls; see Materials and methods). To investigate the possibility of a direct relationship between the decrease in cell viability and the inhibition of cell proliferation, we followed the course of proliferation over 3 days after the addition of metformin. As shown in Fig. 1A, metformin $(0,5$ and $10 \mathrm{mM})$ led to a decrease in cell proliferation in a dose- and time-dependent manner. These results showed that metformin inhibits the proliferation of pancreatic cancer cells.

To study whether metformin affects the cell cycle in Panc1 cells, western blot analysis was used to examine the expression 


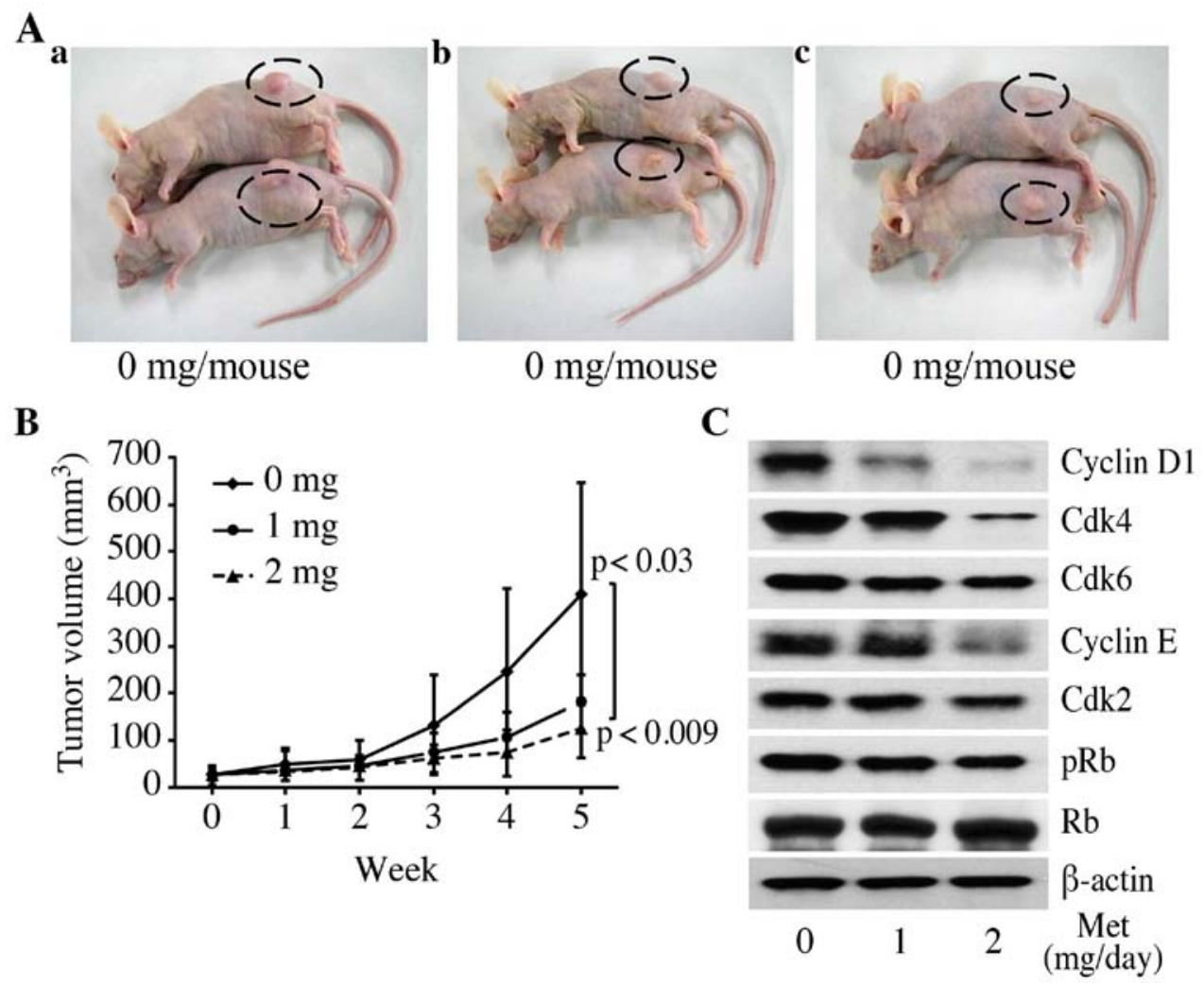

Figure 2. In vivo antitumor effects of metformin (Met) on established pancreatic cancer in nude mice. (A) Representative images of the gross Panc1 tumors from nude mice either left untreated as control (a), or treated with $1 \mathrm{mg}$ (b) or $2 \mathrm{mg}$ (c) Met, respectively. (B) Panc1 cells implanted subcutaneously into the flank regions of nude mice. When a tumor became palpable, 1 and $2 \mathrm{mg}$ Met was intraperitoneally injected for 5 weeks, 5 times/week. Animals in the control group developed rapidly growing subcutaneous pancreatic cancer. In contrast, animals in the Met groups exhibited significantly retarded tumor development. The tumors in the mice treated with $2 \mathrm{mg}$ Met were significantly smaller compared with those in the mice treated with $1 \mathrm{mg}$ Met. Each data point represents the mean \pm SD tumor volume of 10 animals. $\mathrm{P}=0.0207$, one-way analysis of variance, ANOVA; ${ }^{*} \mathrm{P}<0.03$ and ${ }^{* *} \mathrm{P}<0.009$. Tumor volumes $\left(\mathrm{mm}{ }^{3}\right)$ are expressed as: Tumor volume $\left(\mathrm{mm}^{3}\right)=$ [tumor length $(\mathrm{mm})$ x tumor width $\left.(\mathrm{mm})^{2}\right] / 2$. $(\mathrm{C})$ Representative western blot analysis of cell cycle-regulatory protein expression in tumors from mice treated with and without Met. Levels of various cell cycle-related proteins in the tumor tissues treated with Met were reduced as compared with the level in the tissue from the control nude mice.

of various cell cycle-related molecules in Panc1 cells with and without treatment of metformin. Cells were treated with $10 \mathrm{mM}$ metformin or left untreated for 24-72 $\mathrm{h}$. The most remarkable change was the loss of cyclin D1 and Cdk4 protein. Cyclin D1 is a key protein implicated in the transition of the G0/G1 phase. The cyclin D1 and Cdk4 levels declined slightly at $24 \mathrm{~h}$ after the addition of metformin and were no longer detectable after 48 and $72 \mathrm{~h}$. Cdk6, the catalytic subunit of cyclin D1, as well as Cdk4, were decreased at 48 and $72 \mathrm{~h}$ in the metformin-treated cells compared with the untreated cells. As shown in Fig. 1B, we then studied the expression of other cell cycle-related proteins (pRb, Cdk 2 and cyclin E). The protein levels of $\mathrm{Cdk} 2$ and cyclin $\mathrm{E}$ in the cells treated with metformin for 24-72 h decreased slightly when compared with the corresponding levels in the cells not treated with metformin (Fig. 1B). Although the Rb protein level did not change, the phosphorylated $\mathrm{pRb}$ levels decreased progressively in the metformin-treated cells.

Metformin inhibits tumor proliferation in vivo. In order to determine whether or not metformin affects tumor growth in vivo, we injected nude mice subcutaneously (s.c.) with Panc1 cells. Metformin was injected daily intraperitoneally (i.p.) at 1 or $2 \mathrm{mg} / \mathrm{day}$. On the basis of the integrated values of the tumor growth curves, i.p. administration of metformin led to substantial inhibition of tumor growth, by $43.9 \%$ (1 mg/day) and $30.5 \%$ ( $2 \mathrm{mg} /$ day) (Fig. $2 \mathrm{~A}$ and $\mathrm{B}$; $\mathrm{P}=0.0089$, one-way ANOVA). These growth rates were significantly above those of the control $(\mathrm{P}<0.03$ for $1 \mathrm{mg} /$ day and $\mathrm{P}<0.01$ for $2 \mathrm{mg} /$ day $)$. In addition, treatment with $2 \mathrm{mg}$ of metformin significantly inhibited tumor growth compared with the mice treated with $1 \mathrm{mg}$ of metformin $(\mathrm{P}<0.07)$. In the present study, metformin exhibited no apparent changes in mice and did not affect their weight (data not shown). All animals were alive during the experiment.

In order to determine whether or not metformin also affects cell cycle-regulatory protein levels in vivo, we analyzed protein expression using western blot analysis in tumors obtained from the xenograft experiments. Metformin significantly reduced the levels of these proteins (phosphorylated $\mathrm{Rb}$, cyclin D1, Cdk2, Cdk4, Cdk6 and cyclin E) in the treated tumors compared to the levels in controls (Fig. 2C). In contrast, total $\mathrm{Rb}$ was the same irrespective of metformin treatment. These results suggest that, similar to the results of the in vitro observations (Fig. 1B), metformin decreased tumor growth by reducing cell cycle-regulatory protein levels, resulting in G1 cell cycle arrest.

The activity level of tyrosine-activated receptor tyrosine kinases (RTKs) is associated with pancreatic carcinoma. We 


\begin{tabular}{|c|c|c|c|c|c|c|c|c|c|c|c|}
\hline $\begin{array}{c}\text { PY- } \\
\text { control }\end{array}$ & & & & & & & & & & & $\begin{array}{c}\text { PY- } \\
\text { control }\end{array}$ \\
\hline EGFR & ErbB2 & ErbB3 & ErbB4 & FGFR1 & FGFR $2 \alpha$ & FGFR3 & FGFR4 & InsulinR & IGF-IR & Axl & Dtk \\
\hline Mer & HGFR & MSPR & $\operatorname{PDGFR} \alpha$ & PDGFR $\beta$ & SCFR & Flt-3 & M-CSFR & c-Ret & ROR1 & ROR2 & Tie-1 \\
\hline Tie-2 & TrkA & TrkB & TrkC & VEGFR1 & VEGFR2 & VEGFR3 & MuSK & EphA1 & EphA2 & EphA3 & EphA4 \\
\hline EphA6 & EphA7 & EphB1 & EphB2 & EphB4 & EphB6 & $\begin{array}{l}\text { Mouse } \\
\text { IgG1 }\end{array}$ & $\begin{array}{l}\text { Mouse } \\
\text { IgG2A }\end{array}$ & $\begin{array}{l}\text { Mouse } \\
\text { IgG2B }\end{array}$ & $\begin{array}{l}\text { Goat } \\
\text { IgG }\end{array}$ & PBS & \\
\hline $\begin{array}{c}\text { PY- } \\
\text { control }\end{array}$ & & & & & & & & & & & $\begin{array}{c}\text { PY- } \\
\text { control }\end{array}$ \\
\hline
\end{tabular}

PY-control: Phospho-tyrosine positive control
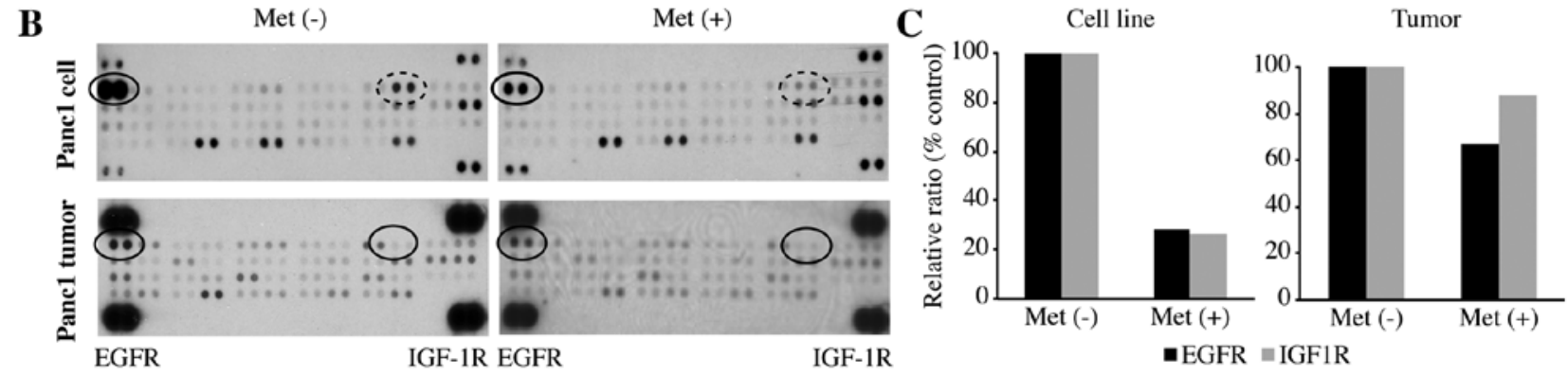

Figure 3. Metformin (Met) inhibits the levels of p-EGFR and p-IGF-1R. (A) Template shows the location of tyrosine kinase antibody spotted onto the RayBio Human Phospho Array kit. (B) Representative expression of various phospho-tyrosine kinase receptors in pancreatic cancer Pancl cells and tumors with or without Met treatment. The reduced expression levels of p-EGFR and p-IGF-1R were detected in Met-treated cells and tumors. (C) The densitometric ratios of the p-EGFR and p-IGF-1R spots for the Met-treated cells and the non-treated cells were 28.1 and $26.3 \%$, respectively. The ratios of p-EGFR and p-IGFR in the Met-treated tumor tissues to non-treated tissues were 66.7 and $87.8 \%$, respectively.

used a phospho-RTK array system to identify the key RTKs associated with pancreatic carcinoma. The antibody array allowed us to simultaneously screen the expression level of 42 different activated RTKs in Pancl cells and tumors, with or without metformin treatment. Compared with the RTK levels in the cell lines and tumors not treated with metformin, p-EGFR was downregulated in the Pancl cell line and tumors treated with metformin. p-IGF-1R was significantly downregulated in the Pancl cell line treated with metformin, but was only slightly downregulated in the tumors.

The densitometric densities of p-EGFR and p-IGF-1R in the cell lines and tumor tissue were visualized in black and white, respectively. The density of the p-EGFR and that of p-IGF-1R obtained from the membrane array were analyzed by means of an Image Station (Eastman Kodak, Rochester, NY, USA). The densitometric ratios of the p-EGFR and p-IGF-1R spots for the metformin-treated cells to cells not treated with metformin were 28.1 and $26.3 \%$, respectively (Fig. 3C). In addition, the ratios of p-EGFR and p-IGFR for metformin-treated tumor tissues to non-treated metformin tumor tissues were 66.7 and $87.8 \%$, respectively (Fig. 3C).

Metformin inhibits the phosphorylation site of EGFR at tyrosine 845. Next, we used the RayBio Human EGFR Phosphorylation Antibody Arrays to assess which of the phosphorylation sites of EGFR are regulated by the antitumor effect of metformin (Fig. 4A). Using this array, we simultaneously detected the relative level of phosphorylation of 17 different specific sites for the human EGFR family in Panc1 cells and tumors with or without metformin treatment. Metformin significantly reduced the phosphorylation of the classical EGFR target residues, EGFR-Y845, as determined by the protein array in vitro and in vivo.

The densitometric densities of EGFR-Y845 in the cell lines and tumor tissues were visualized in black and white, respectively. The density of the EGFR-Y845 obtained from the membrane array was analyzed by means of an Image Station. The densitometric ratio of the EGFR-Y845 spots of the metformin-treated cells to the non-treated metformin cells was $24.1 \%$ (Fig. 4C). In addition, the ratio of EGFR-Y845 in the metformin-treated tumorous tissues to that of the non-treated metformin tumor tissues was $58.0 \%$ (Fig. 4C).

An miRNA expression signature discriminates metformintreated from untreated cells. Using a custom microarray platform, we analyzed the expression levels of 1,212 human miRNA probes in the Pancl cells in vitro and tumor tissues in vivo that were treated with metformin or left untreated. When the expression of miRNAs was studied in the Panc1 cells treated with $10 \mathrm{mM}$ metformin or left untreated in vitro, 78 miRNAs were significantly upregulated in the Panc1 cells after $72 \mathrm{~h}$ of metformin treatment, while 51 miRNAs were downregulated. In the tumor xenograft model, in the metformin group, there were 62 upregulated and 124 downregulated miRNAs among the total 1,212 miRNAs [Gene Expression Omnibus (GEO) accession no. GSE37406]. As shown in Tables I and II, we identified 20 downregulated and upregulated miRNAs, when comparing the metformin-treated cells and tissues and untreated cells and tissues in vitro and in vivo. The 19 miRNAs were matched with miRNAs from both cultured cells and xenograft tissues after metformin treatment. 


\begin{tabular}{|c|c|c|c|c|c|c|c|c|}
\hline P1 & P2 & P3 & Blank & Neg & $\begin{array}{c}\text { EGFR } \\
\text { (Tyr845) }\end{array}$ & $\begin{array}{c}\text { EGFR } \\
\text { (Tyr992) }\end{array}$ & $\begin{array}{c}\text { EGFR } \\
\text { (Tyr1045) }\end{array}$ & $\begin{array}{c}\text { EGFR } \\
\text { (Tyr1068) }\end{array}$ \\
\hline Pl & P2 & P3 & Blank & Neg & $\begin{array}{c}\text { EGFR } \\
\text { (Tyr845) }\end{array}$ & $\begin{array}{c}\text { EGFR } \\
\text { (Tyr992) }\end{array}$ & $\begin{array}{c}\text { EGFR } \\
\text { (Tyr1045) }\end{array}$ & $\begin{array}{c}\text { EGFR } \\
\text { (Tyr1068) }\end{array}$ \\
\hline Blank & Blank & Blank & Blank & $\begin{array}{c}\text { EGFR } \\
\text { (Tyr1068) }\end{array}$ & $\begin{array}{c}\text { EGFR } \\
\text { (Tyrl148) } \\
\end{array}$ & $\begin{array}{c}\text { EGFR } \\
\text { (Tyrl173) }\end{array}$ & $\begin{array}{c}\text { EGFR } \\
\text { (Ser1046/1047) }\end{array}$ & $\begin{array}{c}\text { EGFR } \\
(\text { Ser1070) } \\
\end{array}$ \\
\hline Blank & Blank & Blank & Blank & $\begin{array}{c}\text { EGFR } \\
\text { (Tyrl068) }\end{array}$ & $\begin{array}{c}\text { EGFR } \\
\text { (Tyr1148) }\end{array}$ & $\begin{array}{c}\text { EGFR } \\
\text { (Tyrl173) }\end{array}$ & $\begin{array}{c}\text { EGFR } \\
\text { (Ser1046/1047) }\end{array}$ & $\begin{array}{c}\text { EGFR } \\
(\text { Ser1070) }\end{array}$ \\
\hline $\begin{array}{c}\text { ErbB2 } \\
\text { (Tyr877) }\end{array}$ & $\begin{array}{c}\text { ErbB2 } \\
\text { (Tyr1112) }\end{array}$ & $\begin{array}{c}\text { ErbB2 } \\
\text { (Tyr1221/1222) }\end{array}$ & $\begin{array}{c}\text { ErbB2 } \\
\text { (Tyr1248) }\end{array}$ & $\begin{array}{c}\text { ErbB2 } \\
\text { (Tyr686) }\end{array}$ & $\begin{array}{c}\text { ErbB2 } \\
\text { (Ser1113) }\end{array}$ & $\begin{array}{c}\text { ErbB3 } \\
\text { (Tyr1289) }\end{array}$ & $\begin{array}{c}\text { ErbB4 } \\
\text { (Tyr1284) }\end{array}$ & Blank \\
\hline $\begin{array}{c}\text { ErbB2 } \\
\text { (Tyr877) }\end{array}$ & $\begin{array}{c}\text { ErbB2 } \\
\text { (Tyrl112) }\end{array}$ & $\begin{array}{c}\text { ErbB2 } \\
\text { (Tyr1221/1222) }\end{array}$ & $\begin{array}{c}\text { ErbB2 } \\
\text { (Tyr1248) }\end{array}$ & $\begin{array}{c}\text { ErbB2 } \\
\text { (Tyr686) }\end{array}$ & $\begin{array}{c}\text { ErbB2 } \\
\text { (Ser1113) }\end{array}$ & $\begin{array}{c}\text { ErbB3 } \\
\text { (Tyr1289) }\end{array}$ & $\begin{array}{c}\text { ErbB4 } \\
\text { (Tyr1284) }\end{array}$ & Blank \\
\hline EGFR & ErbB2 & ErbB3 & ErbB4 & Blank & Blank & Neg & Blank & P4 \\
\hline EGFR & ErbB3 & ErbB4 & ErbB5 & Blank & Blank & Neg & Blank & P4 \\
\hline
\end{tabular}

B

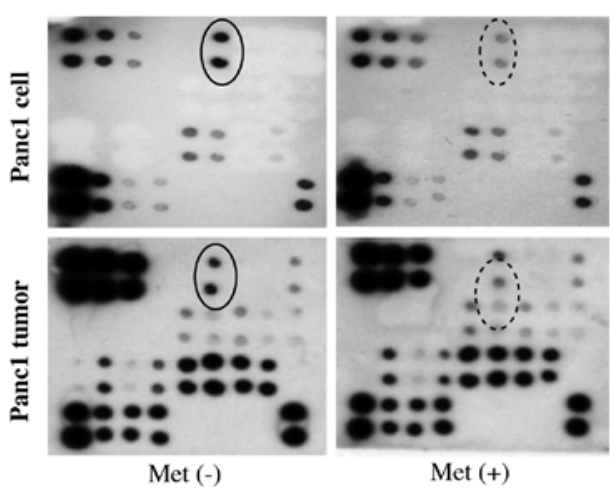

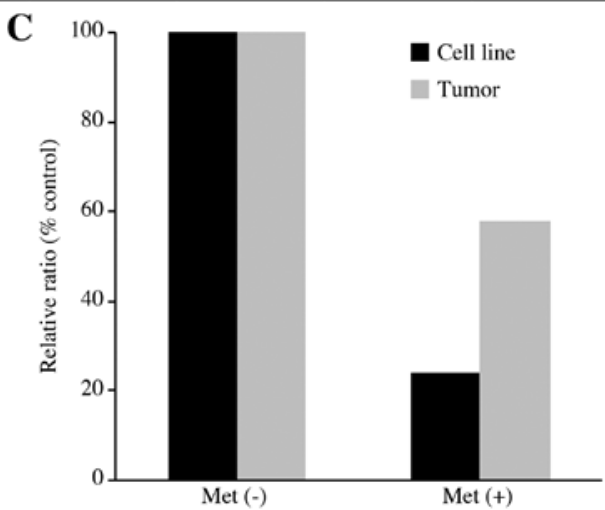

Figure 4. Metformin (Met) inhibits the phosphorylation site of EGFR at tyrosine 845. (A) Template showing the location of tyrosine kinase antibody spotted onto the RayBio Human EGFR Phosphorylation Antibody Array. (B) Representative expression of the phosphorylation of 17 different specific sites for the Human EGFR family in Panc1 cells and tumors with or without Met. The reduced expression levels of EGFR-Y845 were detected in Met-treated cells and tumors. (C) The densitometric ratios of the EGFR-Y845 spots of the Met-treated cells and tumor tissues to the non-treated cells and tumor tissues were 24.1 and $58.0 \%$, respectively.

Table I. Statistical results, chromosomal locations and putative targets of miRNAs in the Panc1 cells treated with metformin, compared with the non-treated cells.

Fold-change

(treated/non-treated)

\section{Downregulated}

1 hsa-miR-7

2 hsa-miR-484

3 hsa-miR-154*

4 hsa-miR-1825

mean $\pm \mathrm{SD}$

$0.494 \pm 0.082$

$0.662 \pm 0.114$

$0.671 \pm 0.314$

$0.693 \pm 0.193$
Chromosomal

P-value localization No. miRNA
Fold-change

(treated/non-treated)

mean \pm SD P-value localization
5 hsa-miR-1180

$0.711 \pm 0.173$

6 hsa-miR-210

7 hsa-miR-138-2*

$0.720 \pm 0.182$

$0.721 \pm 0.130$

8 hsa-miR-3177

9 hsa-miR-3187

10 hsa-miR-93

11 hsa-miR-548y

12 hsa-miR-4296

13 hsa-miR-222*

14 hsa-miR-1203

15 hsa-miR-449b

$0.726 \pm 0.233$

$0.728 \pm 0.132$

$0.728 \pm 0.112$

$0.730 \pm 0.185$

$0.733 \pm 0.194$

$0.736 \pm 0.162$

$0.742 \pm 0.266$

$0.753 \pm 0.236$

$0.753 \pm 0.200$

$0.758 \pm 0.169$

$0.762 \pm 0.283$

$0.763 \pm 0.259$

$0.765 \pm 0.256$
8.91681E-05

5.63397E-06

0.0047

0.0040

0.0004

0.0352

0.0004

0.0016

0.0004

0.0165

0.0107

0.0042

0.0054

0.0162

0.0277

0.0042

0.0002

0.0112

0.0040

0.0266

\section{Upregulated}

$9 q 21.32 \quad 1$ hsa-miR-28-3p $1.695 \pm 1.318$

0.0125

0.0009

0.0004

0.0003

0.0382

0.0050

0.0002

0.0019

0.0005

0.0017

0.0015

0.0157

0.0011

0.0229

0.0004

0.0023

0.0257

0.0280

0.0050

Xq28 19 hsa-miR-934 $1.449 \pm 0.413$

$13 q 14.2 \quad 20$ hsa-miR-616* $1.443 \pm 0.334 \quad 0.0044 \quad 12 q 13.3$

$3 \mathrm{q} 28$

$\mathrm{Xq} 11.23$

$17 q 13.3$

Xq26.3

19q13.42

19

17q23.1

$17 \mathrm{p} 13.3$

17q21.32

Xq11.23

$7 q 32.3$

$17 \mathrm{p} 13.3$

$13 q 14.11$

9q33.3

9

$7 q 32.3$

11q24.1

6q13

Xq26.3 
Table II. Statistical results, chromosomal locations and putative targets of miRNAs in Panc1 tumors treated with metformin, compared with non-treated cells.

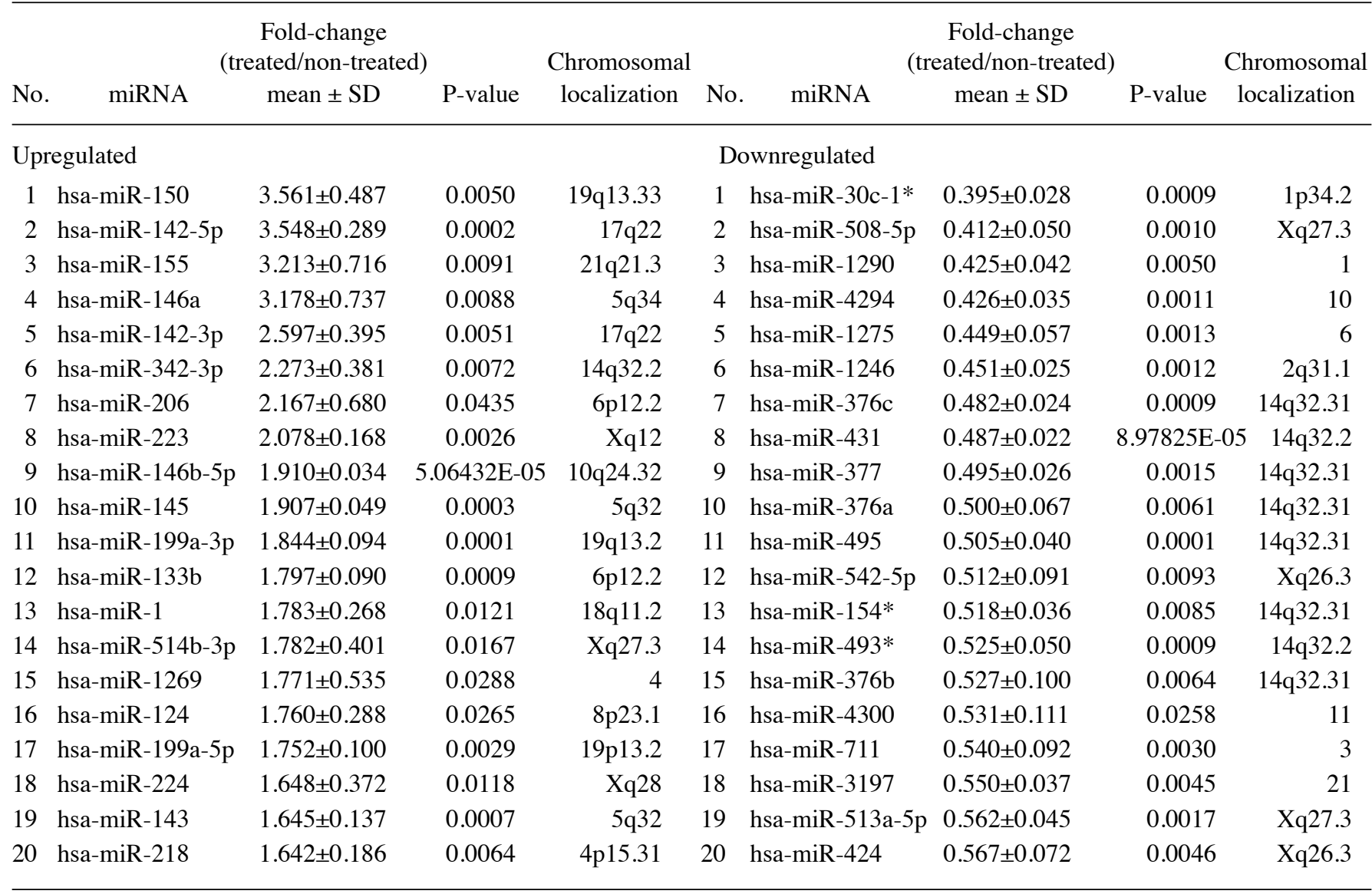

Unsupervised hierarchical clustering analysis using Pearson's correlation showed that the metformin-treated cell lines in vitro and tumor tissues in vivo clustered together and separately from the untreated cell lines (Fig. 5A) and tissues (Fig. 5B). These subsets of 129 miRNAs in the cells and 186 miRNAs in the tissues were found to exhibit significant alterations in expression levels between the metformin-treated and control groups.

\section{Discussion}

Pancreatic cancer is one of the most life-threatening cancers; in 2009 , for example, this cancer accounted for 35,240 deaths in the US, or $6 \%$ of all cancer deaths in that country (16). In spite of the recent progress in surgical procedures, the operative resectability rate of pancreatic cancer remains unsatisfactory at $9-20 \%(17,18)$. Apart from potentially curative surgery, chemotherapy may be applied at advance stages in pancreatic cancer, but is not curative in such cases, and generally has a poor prognosis. Accordingly, there is a strong demand for new curative approaches to pancreatic cancer therapy (19).

Metformin is the drug most commonly used to treat type 2 diabetes, particularly among overweight or obese patients. Metformin lowers circulating glucose levels by reducing hepatic glucose production and increasing the muscle intake of glucose, thereby decreasing circulating levels of insulin (20). Recent data suggest that metformin could protect against cancer and inhibit the proliferation in various cancer cell lines, such as breast, glial and prostate cancer. In addition, we recently reported that metformin inhibits gastric cancer proliferation in vitro and in vivo (9). In addition, another recent study indicated that the use of metformin for diabetes was associated with a decreased risk of pancreatic cancer in women (21). Therefore, various clinical trials on the use of metformin for pancreatic cancer have been conducted worldwide. However, the detailed mechanisms underlying the antitumor effect of metformin on pancreatic cancer remain unknown. In the present study we showed that metformin not only is a very potent inhibitor of human pancreatic cancer cell growth, but also inhibits tumorigenesis in a xenograft model when it is administrated i.p.

The present study was the first to examine the effects of metformin on the proliferation of pancreatic cancer cells. In vitro, a cell proliferation assay indicated that metformin achieved a remarkable decrease in cell viability. Furthermore, in nude mice in vivo the tumor growth of pancreatic cancer was significantly decreased by metformin treatment as compared with that in a control group. These data suggest that metformin may indeed play an inhibitory role in the proliferation of pancreatic cells and tumor growth in vitro and in vivo.

To determine the molecular basis for the inhibitory effects of metformin on the proliferation of pancreatic cancer cells, we analyzed the effect of metformin on the expression of the cell proliferation-regulating proteins cyclin D1, Cdk4, 


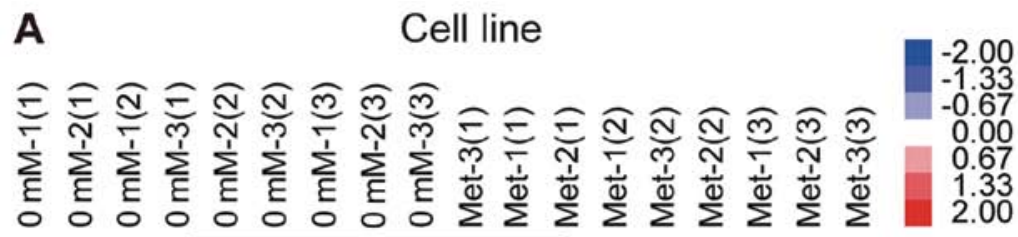

B

Tumor
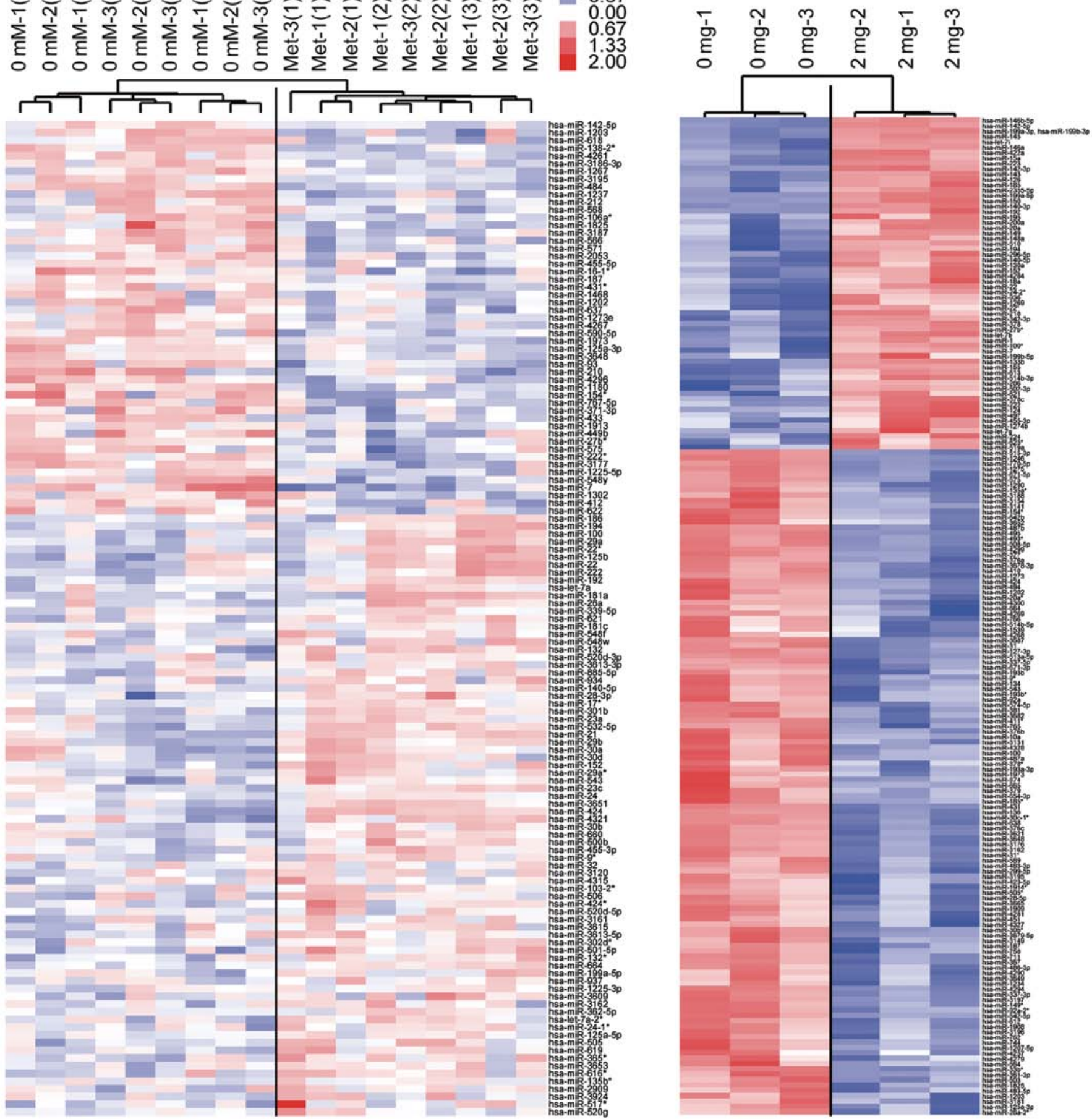

Figure 5. An miRNA expression signature discriminates metformin (Met)-treated cells from untreated cells. (A) Hierarchical clustering of Panc1 cells treated with Met and without Met. Pancl cells were clustered according to the expression profiles of 129 differentially expressed miRNAs between Pancl cells treated with Met and those not treated. (B) Hierarchical clustering of tumor samples from a xenograft animal model with Met and without Met. Tumorous tissues were clustered according to the expression profiles of 186 differentially expressed miRNAs between tumor tissues with Met treatment and those without treatment. (A and B) The analyzed samples are in columns and the miRNAs are presented in rows. The miRNA clustering tree is shown on the left and the sample-clustering tree appears at the top. The color scale shown at the top illustrates the relative expression level of miRNAs; red represents a high expression level, blue represents a low expression level.

Cdk6, Cdk2, cyclin E and phosphorylated pRb. Specific cyclin/cyclin-dependent kinase (Cdk) complexes are activated at different intervals during the cell cycle. Complexes of Cdk4 and Cdk6 with cyclin D1 are required for G1 phase progression, whereas complexes of Cdk2 with cyclin E are required for G1/S transition. In previous studies, downregulation of cyclin D1 in response to metformin has been demonstrated in various cancer cell lines, such as colon, breast, prostate and gastric cancer (9). In the present study, the major cell cycle regulators (cyclin D1, Cdk4, Cdk6, cyclin E, Cdk2, phosphorylated pRb) 
could be intracellular targets of the metformin-mediated antproliferative effect in human pancreatic cancers in vitro and in vivo. These data suggest that the antitumor effect of metformin may be related to the reduction of various cell cycle-related proteins, particularly cyclin D1. Previous studies have shown the enhanced expression of various cell cycle-related molecules (cyclin D1, Cdk4, Cdk6, cyclin E and $\mathrm{Cdk} 2$ ) in various types of cancers, including pancreatic cancer. Therefore, inhibition of these cell cycle-related molecules, including cyclin D1, may be an important molecular target for controlling tumor proliferation.

Our in vitro study was performed using a higher dose of metformin than the human therapeutic concentration $(6-30 \mu \mathrm{M})$. The use of such a high doses has been the subject of criticism of similar studies in other cancer cell types, such as breast, prostate and colon cancer cell lines. However, it is important to consider that cells in culture are grown under hyperglycemic conditions. Tissue culture medium alone contains high concentrations of glucose, and 5-10\% fetal bovine serum is typically added, resulting in excessive growth stimulation. This may explain why, in order to observe the antitumor effects of metformin in cell culture systems, it is necessary to use higher doses than are used in diabetic patients.

Metformin leads to changes in the phosphorylation of various proteins. In breast cancer cells, Liu et al reported that metformin reduced p-EGFR, p-MAPK and p-Src (22). We also detected a reduction in p-EGFR and p-IGF-1R in pancreatic cancers with metformin treatment using protein arrays, particularly in vitro. In the tumor tissue, the decrease in expression in p-EGFR and p-IGF-1R with metformin treatment was mild. The difference in the amount of this reduction reflects the differences between the in vitro and in vivo models. These data suggest that the expression levels of p-EGFR and p-IGF-1R in pancreatic cancer cells are reduced by metformin treatment. The EGFR pathway is important in controlling cell cycle events. The role of EGFR in the cell cycle progression of several human cancers has been studied. Cyclin D1 overexpression in the tumor cells of pancreatic carcinoma tissue is at least partly dependent on the mitogenic effects of EGF signaling through the EGFR (23). Moreover, c-Src is involved in the phosphorylation of EGFR at Tyr845, the expression of which was decreased by the addition of metformin in our studies (24). Similar to EGFR, IGF-1R has been shown to regulate both the expression and activity of many proteins involved in cell cycle progression (25). Decreased expression of IGF-1R induced an antiproliferative effect on human pancreatic cancer cells $(26,27)$. Therefore, metformin blocks the cell cycle in G0/G1 in vitro and in vivo through the reduction of EGFR and IGF-1R activity.

To identify miRNAs associated with the antitumor effect of metformin, we used miRNA expression arrays to detect variations in miRNA profiles in pancreatic cancer cell lines both in culture and in xenograft tumor tissues treated with metformin compared to those not treated with metformin. The cluster analyses we performed clearly demonstrated that metformin treatment affects the extent of miRNA expression in cultured cells and in tumor tissues. In the analyses, we selected sets of miRNAs whose expression levels were altered significantly after metformin treatment. We identified 129 miRNAs differentially expressed (78 upregulated and 51 downregulated) in culture (Table I) and 186 miRNAs differentially expressed (62 upregulated and 124 downregulated) in xenograft tumor tissues (Table II). These miRNAs are meaningful candidates to gauge the effectiveness of metformin treatment and to provide clues to the molecular basis of the anticancer effects of metformin, particularly when mediated with miRNAs.

The expression of hsa-miR-150 was particularly upregulated in metformin-treated tumor tissues, being 3.56 times higher than that in the untreated tumor tissues. Although the expression of hsa-miR-150 is upregulated in gastric and colorectal cancer $(28,29)$, it acts as a tumor-suppressor in malignant melanoma (30). These studies indicate the cell type-specific and context-dependent functions of hsa-miR-150. In pancreatic cancer, hsa-miR-150 overexpression was found to inhibit growth, clonogenicity, migration and invasion, and enhance intercellular adhesion by downregulation of MUC4 (31). Moreover, c-Myb, P2X7 and EGR2 are among the important targets of hsa-miR-150 that have been experimentally validated, since all three factors mediate the tumor-promoting functions of hsa-miR-150 (28,32,33). Zhang et al demonstrated that the overexpression of hsa-miR-150 in $\mathrm{CD} 133^{+}$hepatocellular carcinoma cells induced cell cycle arrest and apoptosis by decreasing c-Myb, cyclin D1 and Bcl-2 (34). Thus, our results suggest that the metformin-induced inhibition of human pancreatic cancer cell proliferation was mediated in part by the tumor-suppression activities caused by upregulation of hsa-miR-150.

In the present study, we found that the expression of hsa-miR-7 extracted from cultured cells was decreased to 0.49 -fold in metformin-treated cells. hsa-miR-7 acts as an important modulator of EGFR-mediated oncogenesis, with potential applications as a novel prognostic biomarker and therapeutic target in multiple human cancer cell types (35-37). In the present study, one reason for the inhibition of EGFR in metformin-treated cells may be mediated by the downregulation of hsa-miR-7.

We also found that members of the let-7 family were upregulated in both cultured cells and tumor tissues treated with metformin ( 2 genes in cultured cells and 3 genes in tumor tissue). The human let-7 family, which contains 13 members, is widely recognized as a class of miRNAs producing a tumorsuppressing effect (38). The members of the let-7 family act as tumor suppressors by binding to target oncogenes, including Ras (39), HMGA2 (40), c-Myc (41) and various cell cycle regulators. In a recent study, we reported that members of the let-7 family are upregulated in metformin-treated gastric cancer cells and tumor tissues (9). Among the let-7 family members upregulated in the metformin-treated tumor tissue in the present study, let-7g, which was 1.3 times higher than that in the untreated tissues, targets cell cycle control genes such as cyclin D1, E2F1, Ras and c-myc and restrains the growth of hepatoma cells (42). In addition, let-7b, the level of which was 1.2 times higher than that in untreated tissue, is overexpressed in melanoma cells in vitro, was found to lead to downregulation of the expression of cyclins D1, D3 and A, as well as to the downregulation of cyclin-dependent kinase (Cdk) $4(43,44)$. Thus, our data suggest that let-7 family members may be candidates for new therapeutic targets in pancreatic cancer.

In the present study, we found only 27 matched miRNAs extracted from cultured cells and tumor tissues after treatment 
with metformin. Although many miRNAs were significantly altered after metformin treatment, we found several differences in the profiles of miRNA expression between the cultured cells and tumor tissues. This discrepancy could reflect the differences between in vitro and in vivo models. In short, metformin is directly exposed to in vitro cultured cells, while intraperitoneally administered metformin is metabolized in vivo. Additionally, tumor cells in mice are affected by the host immune response. Furthermore, there were differences in exposure times and metformin concentrations between the in vitro and in vivo models. Therefore, differences in exposure times and concentrations of metformin may have resulted in the differential expression profiles of miRNAs.

In conclusion, our results revealed that metformin inhibits human pancreatic cancer cell proliferation and tumor growth, possibly by suppressing cell cycle-related molecules via alteration of miRNAs. Metformin is a drug widely used for the treatment of type 2 diabetes with limited side-effects. Therefore, metformin may become a novel and effective therapy for the treatment and long-term management of pancreatic cancer, providing additional benefits at low cost.

\section{Acknowledgements}

We thank Madoka Seguchi, Yuuko Miyawaki and Fuyuko Kokado (Kagawa University) for their excellent technical assistance.

\section{References}

1. Li D, Yeung SC, Hassan MM, Konopleva M and Abbruzzese JL: Antidiabetic therapies affect risk of pancreatic cancer. Gastroenterology 137: 482-488, 2009.

2. Noto H, Goto A, Tsujimoto T and Noda M: Cancer risk in diabetic patients treated with metformin: A systematic review and meta-analysis. PLoS One 7: e33411, 2012.

3. Ben Sahra I, Laurent K, Loubat A, Giorgetti-Peraldi S, Colosetti P, Auberger P, Tanti JF, Le Marchand-Brustel Y and Bost F: The antidiabetic drug metformin exerts an antitumoral effect in vitro and in vivo through a decrease of cyclin D1 level. Oncogene 27: 3576-3586, 2008.

4. Col NF, Ochs L, Springmann V, Aragaki AK and Chlebowski RT: Metformin and breast cancer risk: A meta-analysis and critical literature review. Breast Cancer Res Treat 135: 639-646, 2012.

5. Zhang P, Li H, Tan X, Chen L and Wang S: Association of metformin use with cancer incidence and mortality: A metaanalysis. Cancer Epidemiol 37: 207-218, 2013.

6. Din FV, Valanciute A, Houde VP, Zibrova D, Green KA, Sakamoto K, Alessi DR and Dunlop MG: Aspirin inhibits mTOR signaling, activates AMP-activated protein kinase, and induces autophagy in colorectal cancer cells. Gastroenterology 142: 1504-15.e3, 2012.

7. Wang LW, Li ZS, Zou DW, Jin ZD, Gao J and Xu GM: Metformin induces apoptosis of pancreatic cancer cells. World J Gastroenterol 14: 7192-7198, 2008.

8. Kisfalvi K, Eibl G, Sinnett-Smith J and Rozengurt E: Metformin disrupts crosstalk between $\mathrm{G}$ protein-coupled receptor and insulin receptor signaling systems and inhibits pancreatic cancer growth. Cancer Res 69: 6539-6545, 2009.

9. Kato K, Gong J, Iwama H, Kitanaka A, Tani J, Miyoshi H, Nomura K, Mimura S, Kobayashi M, Aritomo Y, et al: The antidiabetic drug metformin inhibits gastric cancer cell proliferation in vitro and in vivo. Mol Cancer Ther 11: 549-560, 2012.

10. van Rooij E, Sutherland LB, Liu N, Williams AH, McAnally J, Gerard RD, Richardson JA and Olson EN: A signature pattern of stress-responsive microRNAs that can evoke cardiac hypertrophy and heart failure. Proc Natl Acad Sci USA 103: 18255-18260, 2006.

11. Iorio MV and Croce CM: MicroRNAs in cancer: Small molecules with a huge impact. J Clin Oncol 27: 5848-5856, 2009.
12. Iorio MV and Croce CM: MicroRNA dysregulation in cancer: Diagnostics, monitoring and therapeutics. A comprehensive review. EMBO Mol Med 4: 143-159, 2012.

13. Masaki T, Tokuda M, Yoshida S, Nakai S, Morishita A, Uchida N, Funaki T, Kita Y, Funakoshi F, Nonomura T, et al: Comparison study of the expressions of myristoylated alanine-rich $\mathrm{C}$ kinase substrate in hepatocellular carcinoma, liver cirrhosis, chronic hepatitis, and normal liver. Int J Oncol 26: 661-671, 2005.

14. Laemmli UK: Cleavage of structural proteins during the assembly of the head of bacteriophage T4. Nature 227: 680-685, 1970.

15. Towbin H, Staehelin T and Gordon J: Electrophoretic transfer of proteins from polyacrylamide gels to nitrocellulose sheets: Procedure and some applications. Proc Natl Acad Sci USA 76: 4350-4354, 1979.

16. Jemal A, Siegel R, Ward E, Hao Y, Xu J and Thun MJ: Cancer statistics, 2009. CA Cancer J Clin 59: 225-249, 2009.

17. Chua YJ and Cunningham D: Adjuvant treatment for resectable pancreatic cancer. J Clin Oncol 23: 4532-4537, 2005.

18. Oettle H, Post S, Neuhaus P, Gellert K, Langrehr J, Ridwelski K, Schramm H, Fahlke J, Zuelke C, Burkart C, et al: Adjuvant chemotherapy with gemcitabine vs observation in patients undergoing curative-intent resection of pancreatic cancer: A randomized controlled trial. JAMA 297: 267-277, 2007.

19. Komori S, Osada S and Yoshida K: Novel strategy with gemcitabine for advanced pancreatic cancer. ISRN Oncol 2011: 936893, 2011.

20. Vazquez-Martin A, López-Bonetc E, Cufí S, Oliveras-Ferraros C, Del Barco S, Martin-Castillo B and Menendez JA: Repositioning chloroquine and metformin to eliminate cancer stem cell traits in pre-malignant lesions. Drug Resist Updat 14: 212-223, 2011.

21. Bodmer M, Becker C, Meier C, Jick SS and Meier CR: Use of antidiabetic agents and the risk of pancreatic cancer: A casecontrol analysis. Am J Gastroenterol 107: 620-626, 2012.

22. Liu B, Fan Z, Edgerton SM, Deng XS, Alimova IN, Lind SE and Thor AD: Metformin induces unique biological and molecular responses in triple negative breast cancer cells. Cell Cycle 8: 2031-2040, 2009.

23. Poch B, Gansauge F, Schwarz A, Seufferlein T, Schnelldorfer T, Ramadani M, Beger HG and Gansauge S: Epidermal growth factor induces cyclin D1 in human pancreatic carcinoma: Evidence for a cyclin D1-dependent cell cycle progression. Pancreas 23: 280-287, 2001.

24. Biscardi JS, Maa MC, Tice DA, Cox ME, Leu TH and Parsons SJ: c-Src-mediated phosphorylation of the epidermal growth factor receptor on Tyr845 and Tyr1101 is associated with modulation of receptor function. J Biol Chem 274: 8335-8343, 1999.

25. Moschos SJ and Mantzoros CS: The role of the IGF system in cancer: From basic to clinical studies and clinical applications. Oncology 63: 317-332, 2002.

26. Naidu KA, Karl RC, Naidu KA and Coppola D: Antiproliferative and proapoptotic effect of ascorbyl stearate in human pancreatic cancer cells: Association with decreased expression of insulinlike growth factor 1 receptor. Dig Dis Sci 48: 230-237, 2003.

27. Min Y, Adachi Y, Yamamoto H, Ito H, Itoh F, Lee CT, Nadaf S, Carbone DP and Imai K: Genetic blockade of the insulin-like growth factor-I receptor: A promising strategy for human pancreatic cancer. Cancer Res 63: 6432-6441, 2003.

28. Wu Q, Jin H, Yang Z, Luo G, Lu Y, Li K, Ren G, Su T, Pan Y, Feng B, et al: MiR-150 promotes gastric cancer proliferation by negatively regulating the pro-apoptotic gene EGR2. Biochem Biophys Res Commun 392: 340-345, 2010.

29. Lin M, Chen W, Huang J, Gao H, Ye Y, Song Z and Shen X: MicroRNA expression profiles in human colorectal cancers with liver metastases. Oncol Rep 25: 739-747, 2011.

30. Watanabe A, Tagawa H, Yamashita J, Teshima K, Nara M, Iwamoto K, Kume M, Kameoka Y, Takahashi N, Nakagawa T, et al: The role of microRNA-150 as a tumor suppressor in malignant lymphoma. Leukemia 25: 1324-1334, 2011.

31. Srivastava SK, Bhardwaj A, Singh S, Arora S, Wang B, Grizzle WE and Singh AP: MicroRNA-150 directly targets MUC4 and suppresses growth and malignant behavior of pancreatic cancer cells. Carcinogenesis 32: 1832-1839, 2011.

32. Zhou L, Qi X, Potashkin JA, Abdul-Karim FW and Gorodeski GI: MicroRNAs miR-186 and miR-150 down-regulate expression of the pro-apoptotic purinergic $\mathrm{P}_{2} \mathrm{X}_{7}$ receptor by activation of instability sites at the 3 -untranslated region of the gene that decrease steady-state levels of the transcript. J Biol Chem 283: 28274-28286, 2008. 
33. Lin YC, Kuo MW, Yu J, Kuo HH, Lin RJ, Lo WL and Yu AL: $\mathrm{c}-\mathrm{Myb}$ is an evolutionary conserved miR-150 target and miR$150 / \mathrm{c}-\mathrm{Myb}$ interaction is important for embryonic development. Mol Biol Evol 25: 2189-2198, 2008.

34. Zhang J, Luo N, Luo Y, Peng Z, Zhang T and Li S: microRNA150 inhibits human CD133-positive liver cancer stem cells through negative regulation of the transcription factor c-Myb. Int J Oncol 40: 747-756, 2012.

35. Webster RJ, Giles KM, Price KJ, Zhang PM, Mattick JS and Leedman PJ: Regulation of epidermal growth factor receptor signaling in human cancer cells by microRNA-7. J Biol Chem 284: 5731-5741, 2009.

36. Duex JE, Comeau L, Sorkin A, Purow B and Kefas B: Usp18 regulates epidermal growth factor (EGF) receptor expression and cancer cell survival via microRNA-7. J Biol Chem 286: 25377-25386, 2011.

37. Chou YT, Lin HH, Lien YC, Wang YH, Hong CF, Kao YR, Lin SC, Chang YC, Lin SY, Chen SJ, et al: EGFR promotes lung tumorigenesis by activating miR-7 through a Ras/ERK/ Myc pathway that targets the Ets2 transcriptional repressor ERF. Cancer Res 70: 8822-8831, 2010.

38. Boyerinas B, Park SM, Hau A, Murmann AE and Peter ME: The role of let-7 in cell differentiation and cancer. Endocr Relat Cancer 17: F19-F36, 2010.
39. Johnson SM, Grosshans H, Shingara J, Byrom M, Jarvis R, Cheng A, Labourier E, Reinert KL, Brown D and Slack FJ: RAS is regulated by the let-7 microRNA family. Cell 120: 635-647, 2005.

40. Lee YS and Dutta A: The tumor suppressor microRNA let-7 represses the HMGA2 oncogene. Genes Dev 21: 1025-1030, 2007.

41. Osada $\mathrm{H}$ and Takahashi T: let-7 and $m i R-17-92$ : Small-sized major players in lung cancer development. Cancer Sci 102: 9-17, 2011.

42. Lan FF, Wang H, Chen YC, Chan CY, Ng SS, Li K, Xie D, He ML, Lin MC and Kung HF: Hsa-let-7g inhibits proliferation of hepatocellular carcinoma cells by downregulation of $c-M y c$ and upregulation of $p 16^{I N K 4 A}$. Int J Cancer 128: 319-331, 2011.

43. Fu TY, Chang CC, Lin CT, Lai CH, Peng SY, Ko YJ and Tang PC: Let-7b-mediated suppression of basigin expression and metastasis in mouse melanoma cells. Exp Cell Res 317: 445-451, 2011.

44. Schultz J, Lorenz P, Gross G, Ibrahim S and Kunz M: MicroRNA let $-7 b$ targets important cell cycle molecules in malignant melanoma cells and interferes with anchorage-independent growth. Cell Res 18: 549-557, 2008. 